\title{
Management and Soil Conditions Influence Common Scab Severity on Potato Tubers Via Indirect Effects on Soil Microbial Communities
}

\author{
Emily W. Lankau, ${ }^{1,2}$ Dianne Xue, ${ }^{2}$ Rachel Christensen, ${ }^{2}$ Amanda J. Gevens, ${ }^{2}$ and Richard A. Lankau $2, \dagger$ \\ ${ }^{1}$ Department of Animal Sciences, University of Wisconsin, Madison, WI \\ 2 Department of Plant Pathology, University of Wisconsin, Madison, WI \\ Accepted for publication 7 January 2020.
}

\begin{abstract}
Common scab, caused by Streptomyces scabies and related species, is a potato tuber blemish disease that causes reductions in marketable yield worldwide. Evidence of suppression of common scab by indigenous soil microbial populations has been found in several studies. However, we lack a comprehensive understanding of how common scab severity relates functionally to potato varieties, farming systems, soil physical and chemical properties, and soil microbial communities. These factors may affect disease directly or indirectly by affecting one of the other variables. We performed a survey of 30 sampling locations across 12 fields in Wisconsin and used structural equation modeling to disentangle the direct effects of potato market classes, farm
\end{abstract}

ABSTRACT management (conventional versus organic), and soil physiochemical properties on common scab severity from their indirect effects mediated through soil bacterial and fungal communities. We found that, although potato market classes affected disease severity directly, the effects of farm management and soil physiochemistry were best explained as indirect, mediated by their impacts on soil bacterial communities. This suggests that evaluating the consequences of specific management practices for soil microbial communities may be useful for understanding disease pressure across fields.

Keywords: ecology and epidemiology, bacteriology
Potato plants can be infected by a number of soilborne pathogens that affect early establishment, vegetative growth, and tuber quality. Blemishes associated with soilborne pathogens can reduce both quantity and quality of tubers, rendering many unmarketable. Management of soilborne pathogens is challenging; efforts to reduce incidence or severity of disease may include repeated application of some of the most agroecologically impactful pesticides, which may reduce disease damage but do not eliminate the problem from affected fields (Braun et al. 2017; Colquhoun et al. 2017; Powelson and Rowe 2008).

Globally, several soilborne, gram-positive, filamentous bacterial species in the genus Streptomyces, particularly Streptomyces scabies, cause common scab, a potato tuber disease that causes reductions in quality and usable yield (Braun et al. 2017; Loria et al. 2006; Wanner 2009). Common scab blemishes and secondary infections can result in food losses of up to $22 \%$ (United Kingdom, FAOSTAT [FAO 2014]), especially in production regions of the northern latitudes, including the northcentral region of the United States.

In Wisconsin, common scab is managed through a combination of cultivar selection, crop rotation, and additional cultural management practices. Some potato varieties are considered partially resistant to the disease, which may be owing to physical aspects of the tuber and/or detoxification of pathogen-produced toxins (thaxtomins) (Braun et al. 2017). Crop rotation is an important strategy to reduce prevalence of the pathogen in the soil, but $S$. scabies can persist for several years between potato crops (Braun et al. 2017),

†Corresponding author: R. A. Lankau; lankau@wisc.edu

Funding: This work was supported by the Wisconsin Potato and Vegetable Grower's Association and USDA Hatch Award WIS01946.

*The $\boldsymbol{e}$-Xtra logo stands for "electronic extra" and indicates that one supplementary figure and supplementary tables are published online.

The author(s) declare no conflict of interest.

(c) 2020 The American Phytopathological Society and inoculum can be introduced on the potato seed piece (Webster et al. 2018). Soil management practices to promote acidic soil $\mathrm{pH}$ and adequate soil moisture during tuber initiation can reduce scab symptoms (Braun et al. 2017). Although some chemical treatments have shown partial control of common scab, no currently available treatments provide highly effective and consistent control across sites (Braun et al. 2017; Powelson and Rowe 2008).

All soils contain diverse microbial communities, and successful soilborne pathogens must be able to persist in the face of competition from indigenous microbial communities. Soils that suppress common scab have been reported in the literature, and subsequent research has identified numerous antagonistic soil microbial taxa that may play a role in suppression (Hiltunen et al. 2009; Liu et al. 1995; Lorang et al. 1995; Meng et al. 2012; NeenoEckwall et al. 2001; Rosenzweig et al. 2012). Nonpathogenic members of the Streptomyces genus have been of particular interest for common scab suppression because of production of antibiotics and hypothesized role as ecological competitors of pathogenic Streptomyces (Liu et al. 1995; Neeno-Eckwall et al. 2001; Schottel et al. 2001). However, attempts to use these species as biocontrol inoculants at the field scale have had inconsistent effects (Liu et al. 1995; Ryan et al. 2004; Schottel et al. 2001; Sun et al. 2015). Thus, improved understanding of the factors promoting naturally suppressive soil communities may be of value in addition to attempts to develop specific biocontrol inoculant products.

Strong relationships between certain soil microbial populations and suppression of common scab raise the broader question of whether management practices and soil conditions known to reduce common scab severity reflect direct effects on the pathogen or indirect effects mediated through changes in soil microbial communities. Here, we surveyed common scab severity from 15 fields across Wisconsin and measured soil chemistry and bacterial and fungal community composition in soils from each field. We tested whether scab severity correlated with management practices at a very broad scale (conventionally versus U.S. Department of Agriculture [USDA]certified organically managed), potato cultivars (combined into market classes), soil chemistry, and bacterial and fungal community composition in the sampling locations measured early 
in tuber development. Then, we used structural equation modeling to determine which of these variables exert direct effects on disease severity and which have primarily indirect effects mediated through soil microbial communities.

\section{MATERIALS AND METHODS}

During the summer of 2015, we identified a total of 12 fields planted to potato distributed across Wisconsin that varied in management practices (USDA-certified organic or conventionally managed), soil types, and potato varieties (Supplementary Table S1). Early in the growing season (during June and July), we took soil cores from between one and four locations depending on field size. Our largest fields were conventionally managed, center pivotirrigated fields approximately 16 ha in size, which were sampled from four locations. Other fields ranged from a few acres, from which we took two samples, down to $<10 \mathrm{~m}$ in length and width, from which we took only a single sample. Sampling locations within a field were chosen haphazardly, but they were at least $20 \mathrm{~m}$ apart, and the GPS coordinates of each sampling location were recorded. Each sample consisted of three soil cores (2-cm diameter and $15-\mathrm{cm}$ depth) pulled from the base of three adjacent potato plants. The three cores per sampling location were homogenized in the field, but distinct sampling locations within a single field were collected and processed separately. In total, 30 separate soil samples were used for this dataset from a total of 12 fields (Supplementary Table S1 has details of each sample and field). These 30 samples were part of a larger soil-sampling effort described in Xue et al. (2018).

We revisited fields during September 2015 shortly before harvest. We used GPS coordinates to collect 20 tubers from each prior sampling location. Each tuber was visually scored for common scab severity using a published scale (hereafter scab severity score) (Webster et al. 2018). The scale was a score based on lesion coverage (0: no lesions; 1 : 1 to $10 \%$ of tuber surface; $2: 11$ to $25 \%$ of tuber surface; $3: 26$ to $50 \%$ of tuber surface; $4: 51$ to $75 \%$ of tuber surface; and $5:>75 \%$ of tuber surface) multiplied by a phenotype score based on the nature of the lesions (0: none; 1: small, superficial lesions $<5 \mathrm{~mm}$; 2 : large, coalescing superficial lesions $>5 \mathrm{~mm}$; 3: small raised lesions $<5 \mathrm{~mm}$; 4 : large, coalescing raised lesions $>5 \mathrm{~mm}$; and 5: pitted lesions).

Soil nutrient testing was performed on bulk soil from each field. Because we expected soil physical and chemical characteristics to be fairly homogenous within fields, for fields with multiple sampling locations we combined bulk soils from each sample and submitted one homogenized sample for analysis. Soil samples were submitted to the University of Wisconsin Soil and Forage Laboratory (https://uwlab.soils.wisc.edu) for their routine analysis, which included $\mathrm{pH}$, percentage of organic matter (\%OM; loss on ignition), phosphorus (P; parts per million; Bray I extraction), and potassium (K; parts per million; Bray I extraction). Soil texture was approximated for each field using the USDA Web Soil Survey for each specific sampling location. The dominant soil series for each location was recorded, and soil series were grouped into three categories based on soil texture: loamy sand, sandy loam, or silt loam.

Molecular characterization of bacterial and fungal communities. Sample processing and extraction. Soil samples for microbial community analysis were transported to the laboratory on ice and stored at $-30^{\circ} \mathrm{C}$ until DNA extraction. Soil DNA extractions were performed on $1 \mathrm{~g}$ of wet soil using the E.Z.N.A. Soil DNA kit (Omega Bio-tek, Norcross, GA) following the manufacturer's protocol. DNA extracts were quantified with a NanoDrop spectrophotometer (Thermo Scientific, Grand Island, $\mathrm{NY}$ ), and samples were standardized to $10 \mathrm{ng} / \mu \mathrm{l}$ with sterile water for use as PCR templates. Extractions occurred randomly with respect to field location, and all samples were processed in a single batch using the same kit.
Library preparation. Primers for amplicon barcoding were designed using the TaggiMatrix spreadsheet courtesy of Travis C. Glenn, University of Georgia (Glenn and Faircloth 2013). Internal fusion PCR primers contained a binding region for either the fungal (internal transcribed spacer 2 [ITS2] region) or bacterial (16S V4 to $\mathrm{V} 5$ region) biomarker fused to a variable-length index barcode ( 5 to $8 \mathrm{bp}$ ) and priming regions for the Nextera read primers. Characterization of fungal communities was facilitated by incorporating degenerate binding regions for the ITS2 marker (ITS3KYO2 [Toju et al. 2012] and ITS4 [White et al. 1990]). Bacterial and archaeal communities were characterized using the $515 \mathrm{f}$ (Caporaso et al. 2011) and 926r (Parada et al. 2016) primer sets. Variable-length barcodes at the beginning of each amplicon served two functions: increasing the number of samples that could be multiplexed in a single run and staggering the starting position of the amplicon to increase the sequence diversity within the library. External fusion PCR primers contained a 14-bp overlap to the trailing end of the internal primers followed by either an 8-bp i7 index and P7 flow cell adapter sequence or an i5 index 7-bp spacer and P5 flow cell adapter (Lankau and Keymer 2016).

The first round of PCR amplified the ITS2 or $16 \mathrm{~S} \mathrm{V4}$ to V5 marker and tagged each end of the amplicons with one of eight variable-length (5- to 8-bp) barcodes along with priming regions for the Nextera read primers. For the fungal ITS2 region, PCR was performed in $10-\mu \mathrm{l}$ reactions using $0.2 \mu \mathrm{l}$ of a hot-start, high-fidelity polymerase (Clontech Prime Star GLX; Takara BioUSA, Inc., Mountain View, CA) with $2 \mu \mathrm{l}$ of its $5 \times$ buffer, $0.8 \mu \mathrm{l}$ of dNTPs (at $10 \mathrm{nM}$ concentration), $0.25 \mu \mathrm{l}$ of each primer (at $10 \mathrm{nM}$ ), $0.7 \mu \mathrm{g}$ of T4 gene 32 protein, and $10 \mathrm{ng}$ of template DNA. Thermal cycling conditions included a 5 -min hot start at $98^{\circ} \mathrm{C} ; 35$ cycles of denaturing $\left(98^{\circ} \mathrm{C}\right.$ for $\left.30 \mathrm{~s}\right)$, annealing $\left(50^{\circ} \mathrm{C}\right.$ for $\left.45 \mathrm{~s}\right)$, and extension $\left(68^{\circ} \mathrm{C}\right.$ for $\left.1 \mathrm{~min}\right)$; and a final extension of $15 \mathrm{~min}$ at $68^{\circ} \mathrm{C}$. Successful amplification was verified using agarose gel electrophoresis. For the $16 \mathrm{~S}$ region, the PCR recipe was identical, but the thermocycling program was altered: 5 -min hot start at $98^{\circ} \mathrm{C}$; 35 cycles of denaturing $\left(98^{\circ} \mathrm{C}\right.$ for $\left.45 \mathrm{~s}\right)$, annealing $\left(50^{\circ} \mathrm{C}\right.$ for $\left.45 \mathrm{~s}\right)$, and extension $\left(68^{\circ} \mathrm{C}\right.$ for $\left.1 \mathrm{~min}\right)$; and a final extension of $15 \mathrm{~min}$ at $68^{\circ} \mathrm{C}$.

The second round of PCR added the P5 and P7 flow cell adapters to prepare the library for sequencing on an Illumina MiSeq along with an external set of sample barcodes located between the flow cell adaptors and read primers. PCR was performed in $25-\mu \mathrm{l}$ reactions using $0.5 \mu \mathrm{l}$ of a hot-start, high-fidelity polymerase (Clonetech Prime Star GLX) with $5 \mu$ l of its $5 \times$ buffer, $2 \mu$ l of dNTPs (at $10 \mathrm{nM}$ concentration), $1 \mu \mathrm{l}$ of each primer (at $10 \mathrm{nM}$ ), and $1 \mu \mathrm{l}$ of product from the first PCR as template. Thermal cycling conditions included a 5-min hot start at $98^{\circ} \mathrm{C} ; 15$ cycles of denaturing $\left(98^{\circ} \mathrm{C}\right.$ for $30 \mathrm{~s})$, annealing $\left(60^{\circ} \mathrm{C}\right.$ for $\left.45 \mathrm{~s}\right)$, and extension $\left(68^{\circ} \mathrm{C}\right.$ for $\left.1 \mathrm{~min}\right)$; and a final extension of $10 \mathrm{~min}$ at $68^{\circ} \mathrm{C}$.

Amplicons were cleaned with the Omega BioTek E-Z 96 Cycle Pure kit. Purified products were quantified using a Qubit 2.0 fluorometer with the Qubit dsDNA HS assay (Thermo Scientific, Grand Island, NY). Fungal and bacterial amplicons from soil samples were pooled at equal concentration and sequenced with one run of the Illumina MiSeq using V3 chemistry with paired-end sequencing.

Bioinformatics. Because we used a mixture of external and internal barcodes (see above), we used several bioinformatics steps to separate sequences from each sample, cluster sequence reads, and assign taxonomic identities, all within the QIIME2 pipeline. Samples with distinct external barcodes were provided as separate fastq files by the University of Wisconsin-Madison Biotechnology Center. Sequences were separated by external barcode sequences by the University of Wisconsin Biotechnology Center and then, separated by internal barcode sequence using the cut-adapt plugin within QIIME2. Demultiplexed sequences were filtered for quality and assigned to amplicon sequence variants (ASVs; equivalent to $100 \%$ identity operational taxonomic units) using the DADA2 program (Callahan et al. 2016) as implemented in the QIIME2 
pipeline (Bolyen et al. 2019). Nonsingleton ASVs were identified to the lowest confident taxonomic level using the naïve Bayesian classifier RDP using the Greengenes reference database (version 13_8) for 16S reads (Wang et al. 2007) and the UNITE database (version 18.11.2018 [Nilsson et al. 2019]) for ITS reads. We used the taxonomic assignments to create additional summaries at the genus and phyla levels using the "taxa collapse" plugin within QIIME2, which sums the sequence reads for all ASVs sharing the same taxonomic assignment through a specified level.

Rarefaction curves for bacterial and fungal communities show most samples reaching an asymptote within approximately 1,000 sequence reads for bacteria and approximately 500 sequence reads for fungi (Supplementary Fig. S1). For all subsequent analyses, sequence reads within each sample were rarified to the lowest sequence depth in the sample set $(1,072$ sequences for bacteria and 597 for fungi) using the rrarefy function in the vegan package in $\mathrm{R}$ (Oksanen et al. 2015). This creates a randomly subsampled set of sequences for each sample to allow assessments of community composition unbiased by differences in sampling effort among samples.

Statistical analyses. We used linear models to relate the scab severity score as the dependent variable to our two field attributes (potato market class and management practice). We lumped potato varieties into one of two market class categories: russet or a combination category including table and chipping varieties with yellow or white skin because these categories roughly reflect genetic groupings (Hirsch et al. 2013).

We used linear models to relate common scab severity to abiotic soil properties. First, we calculated univariate regressions of common scab against each of the four chemical variables $(\mathrm{pH}, \%$ $\mathrm{OM}, \mathrm{K}$, and P) and soil texture class separately. Second, we used principal component (PC) analysis to summarize the variation among the four intercorrelated soil chemical variables (\%OM, P, K, and $\mathrm{pH}$ ) into two orthogonal variables. The first $\mathrm{PC}$ accounted for $45.7 \%$ of the variation and loaded positively on \%OM and $\mathrm{K}$. The second $\mathrm{PC}$ accounted for $30.4 \%$ of the variation and was positively correlated to $\mathrm{P}$ and $\mathrm{pH}$. We then used a multiple regression to compare common scab severity with the first two PCs.

We used permutation multivariate analysis of variance (MANOVA) to compare soil bacterial and fungal composition with common scab severity at the ASV and genus levels using the adonis function in the vegan package in $\mathrm{R}$ (Oksanen et al. 2015). These models use random permutations of the observed data to generate a null distribution of effect sizes with which the observed effect is compared for significance testing. Because market class and management practices might effect both common scab severity and microbial community composition independently, we ran the models using unconstrained permutations as well as with permutations constrained to occur only within market class or only within management categories to control for the effect of these potential confounding factors. We used principal coordinates analysis (PCoA) with a Bray-Curtis dissimilarity metric to visualize differences among bacterial and fungal communities.

As an exploration of specific microbial taxa that may underlie relationships with common scab symptoms, we calculated the correlation between the relative abundance of each bacterial ASV, genus, and phyla in a community with the common scab lesion coverage of that sample. Pearson correlations were used here in all other analyses. We restricted the analysis to only those taxa that were detected in at least 10 samples (one-third of the dataset) to ensure robust correlations (there were $21 \mathrm{ASV}$, 79 genera, and 14 phyla present in 10 or more samples). For each set of correlations, we used the false discovery rate approach to control for the high number of simultaneous statistical tests (Benjamini and Hochberg 1995).

Finally, because all of the individual relationships between management practices, potato market classes, abiotic soil properties, and soil microbial communities may have overlapping effects on soil microbiome composition, we used structural equation modeling to tease apart the direct and indirect effects of these variables on common scab severity (Grace 2006). To incorporate metrics for all four variable types into a single modeling framework, we made the following simplifying assumptions.

1) We used the first two soil chemistry PCs to represent soil abiotic conditions. Because common scab severity did not differ between soil texture classes, this variable was not included in our model.

2) We used the first principal coordinates axis from bacterial and fungal community ordinations at the genus level of taxonomic resolution. We used the genus level of resolution because our perMANOVA analysis indicated a stronger link to common scab severity at this taxonomic resolution compared with the ASV level. Although representing the highly multivariate microbial composition data in just one axis each for bacteria and fungi necessarily leads to loss of information, these axes captured the most dominant gradients in community structure.

To specify our model, we considered management practice, potato variety class, and soil PC1 and PC2 as fully exogeneous variables, meaning that variation in these factors was not caused by variation in any other measured factor. Some factors can only act on other variables because they are determined by external factors that are not part of the causal pathway. Whether to use organic or conventional management approaches and which potato market class to plant are decisions made by growers that can affect downstream outcomes but cannot themselves be affected by factors in the causal pathway. In contrast, soil chemistry variables $(\mathrm{pH}, \% \mathrm{OM}, \mathrm{K}$, and $\mathrm{P}$ ) may primarily reflect underlying soil conditions owing to bedrock materials and glaciation history, but they can also be influenced by grower management decisions (Ge et al. 2011; Norris and Congreves 2018). Additionally, neither soil chemistry nor prevailing management practices are distributed randomly across the landscape in Wisconsin. Rather, organically managed vegetable farms tend to be located on more fertile, richer soils, whereas large-scale conventional potato farms are typically found on sandier soils.

We allowed for bidirectional correlations between each of the exogenous factors to account for the tendency for organic versus conventional farms to be located on different soil types. We included the bacterial and fungal PCoA axes as intermediary variables, with potential causal links from each exogenous variable to each microbial variable. Finally, we included common scab severity as our final endogenous outcome variable, and we included potential causal links from each exogenous variable and each intermediary variable to this outcome. In total, this resulted in an initial model with 27 free parameters to link the seven measured variables. We used the lavaan package in $\mathrm{R}$ to estimate parameter values and derive a $\chi^{2}$ statistic measuring overall goodness of fit and the Akaike information criterion (AIC) value for use in model selection (Yves 2012). We then used a backward stepwise approach to model simplification, removing the parameter with the lowest associated $z$ statistic (and thus, highest $P$ value) and comparing the AIC of the reduced model to the original. We continued removing one parameter at a time until we reached a model in which the AIC value was not improved by the removal of any additional parameters. We considered this the optimal model, which was used for interpretation.

\section{RESULTS}

Common scab severity versus field characteristics. Severity of common scab differed based on the combination of potato market class and management category, with the highest disease severity found on yellow/white varieties from organically managed fields; there was little difference in severity among the other three combinations (management $\times$ market class interaction, 
$\left.F_{1,26}=36.10, P<0.0001\right)$ (Fig. 1). Common scab severity also correlated with soil chemical variables. When regressed on each soil chemical variable separately, common scab severity was positively correlated with $\mathrm{pH}(r=0.45, t=2.67, P=0.013), \% \mathrm{OM}$ $(r=0.445, t=2.63, P=0.014)$, and $\mathrm{K}(r=0.389, t=2.24, P=0.034)$ and negatively associated with $\mathrm{P}(r=-0.540, t=-3.39, P=0.002)$. However, the soil chemical variables were correlated to each other as well. Therefore, we used PC analysis to reduce the four variables down to two orthogonal variables that explained $76 \%$ of the total variation among samples. Using the $\mathrm{PC}$ axes in a multiple regression on common scab severity, the first PC axis (PC1) was highly significant (estimate $=0.555, t=4.288, P=0.0002$ ) (Fig. 2A), whereas the second PC axis (PC2) was not (estimate $=$ $-0.030, t=-0.191, P=0.850)$. High values of PC1 generally

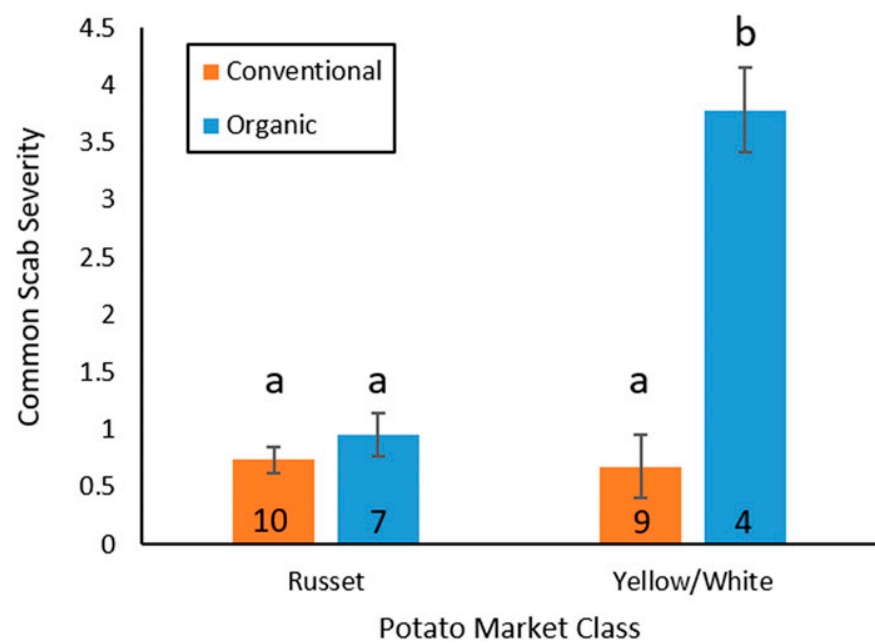

Fig. 1. Average common scab severity in each combination of market class and management practice with standard errors. Sample size is shown at the base of each bar. Each sample represents the average score for 20 tubers scored per sampling location. Bars sharing the same letter are not statistically different according to Tukey's honestly significant difference multiple comparison test. reflected increasing $\mathrm{OM}$ and $\mathrm{K}$, lower levels of $\mathrm{P}$, and more neutral pH (Fig. 2B). Silt loam soils had higher values on the PC1 axis compared with sandier soils. High values of PC2 reflected increasing soil $\mathrm{P}$ as well as increasing $\mathrm{pH}$, and it was not associated with soil texture. Finally, common scab severity did not vary consistently across the three soil textural classes in our dataset $\left(F_{2,26}=\right.$ $2.365, P=0.113)$.

Common scab association with soil microbial composition. Common scab severity was significantly associated with both bacterial and fungal composition measured at the ASV and genus levels (Fig. 3 and Table 1) and bacterial but not fungal composition at the phyla level. These relationships remained significant, although more weakly so, when constraining permutations within market classes and management categories (Table 1).

Correlation of bacterial genera and phyla to common scab severity. After correcting for multiple comparisons, common scab severity in a field location was significantly positively correlated with 1 of 22 ASVs and 15 of 79 genera that met our criteria of detection (present in at least 10 sampling locations). Two ASVs and four genera were significantly negatively correlated with common scab severity. Negatively correlated taxa came from the Actinobacteria (two genera) as well as the genera Bacillus and Janthinobacterium (Supplementary Tables S2 and S3). Positively associated taxa spanned a range of phyla (especially Proteobacteria and Acidobacteria) (Supplementary Tables S2 and S3). At a coarser scale, common scab severity in a sampling location was correlated to the relative abundance of several bacterial phyla. Common scab severity was lowest in communities with high relative abundance of Actinobacteria (Supplementary Table S4). High severity of common scab was correlated with increasing relative abundance of three bacterial and one archaeal phyla (Nitropirae, Verrumicrobiota, Acidobacteria, and Crenarcheota) (Supplementary Table S4). Common scab severity was not significantly correlated to any fungal ASV or genera after controlling for multiple comparisons, but it was positively correlated with the relative abundance of the Mortierellomycota phylum (Supplementary Tables S5, S6, and S7).

Structural equation modeling of common scab severity. When viewed in isolation, common scab severity was associated with potato market classes, management practices, soil chemistry,
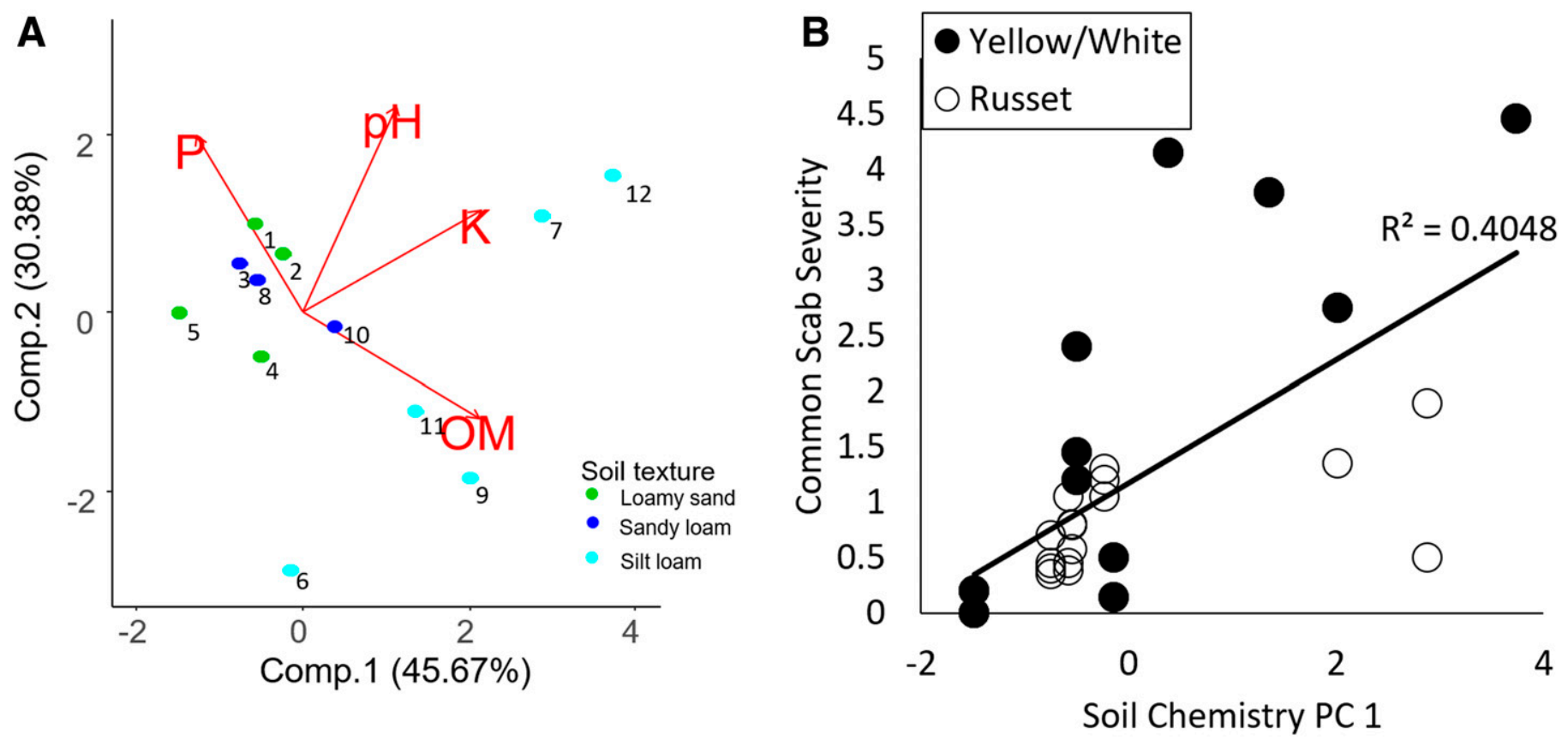

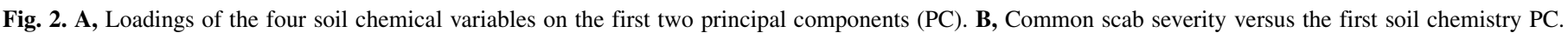

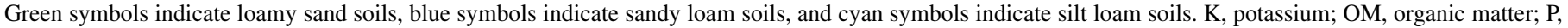
phosphorus. 
and soil microbial communities. However, all of these factors are themselves intercorrelated, making it difficult to separate direct from indirect relationships with disease. We developed a structural equation model based on a priori information on possible causal pathways between each environmental variable and common scab

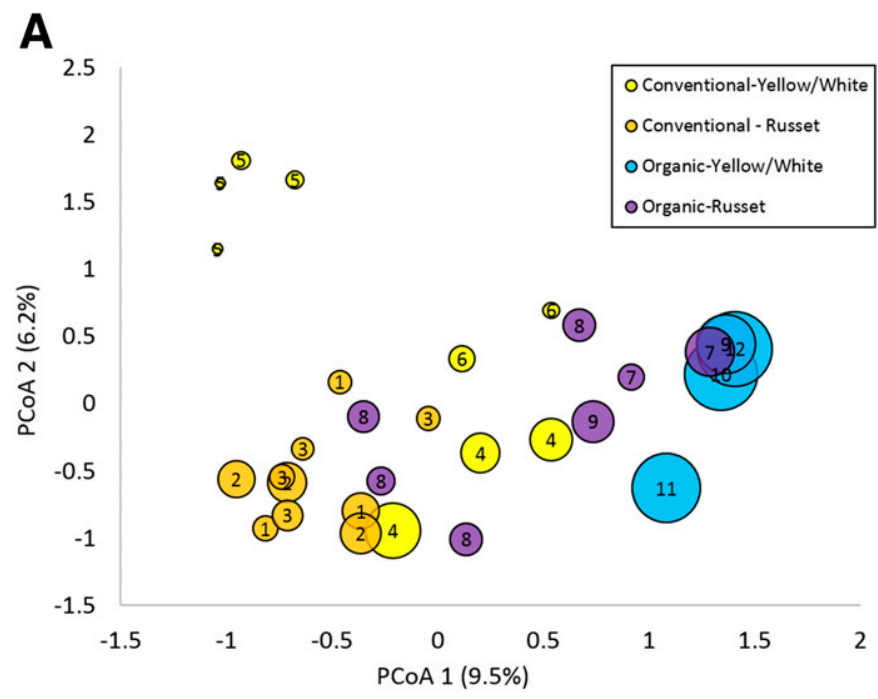

B

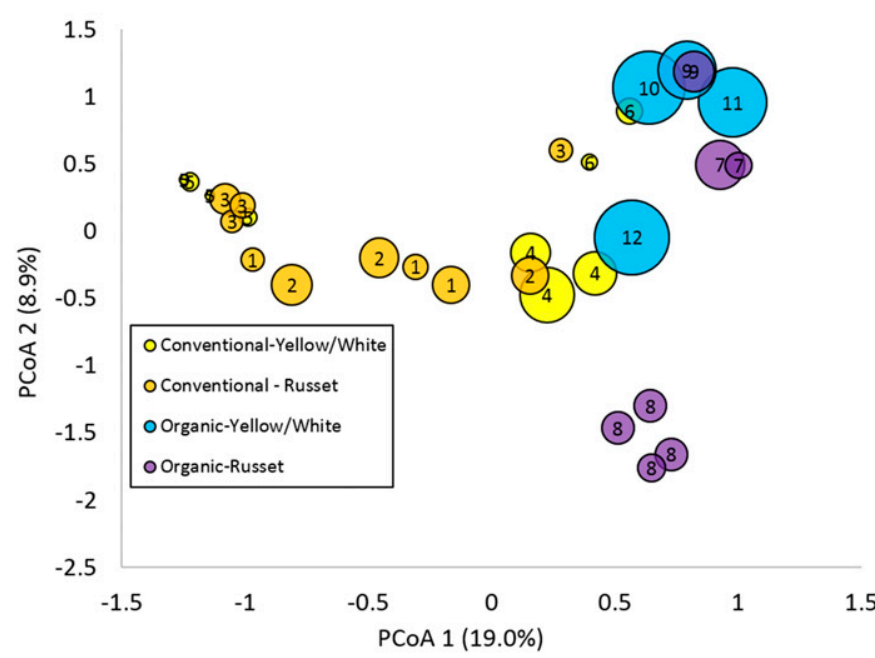

Fig. 3. Principal coordinates analysis (PCoA) of $\mathbf{A}$, bacterial and $\mathbf{B}$, fungal composition based on amplicon sequence variants. PCoA was calculated from Bray-Curtis dissimilarities. Symbol size reflects common scab severity, whereas color reflects market classes and management practices. Percentages refer to the percentages of total compositional variation explained by each axis. severity, resulting a model with 27 free parameters, a $\chi^{2}$ value of $P=$ 1.00, and an AIC value of 402.251. Stepwise elimination of the individual path with the highest associated $P$ value eventually led to a reduced model with 21 free parameters, a $\chi^{2}$ value of $P=0.936$, and an AIC value of 392.435. Further reduction of parameters from this model did not lower the AIC value, and therefore, this model was chosen as our optimal representation of the data. The final model structure is visualized in Figure 4, and model outputs are available in Supplementary Table S7.

\section{DISCUSSION}

Many factors, including management practices, soil chemistry, potato market class, and soil microbial communities, have been associated with occurrence and severity of common scab in potatoes (Liu et al. 1995; Mizuno et al. 1998; Rosenzweig et al. 2012; Ryan et al. 2004; Sagova-Mareckova et al. 2015). In this study, we also found that all of these factors in isolation had demonstrable relationships to scab severity in the field setting. Common scab symptoms were i) higher on cultivars from the table white/yellow/ chipping market class versus the russet class in organically but not conventionally managed fields, ii) increased in soils with more neutral $\mathrm{pH}$ and higher $\mathrm{OM}$, and iii) correlated positively or negatively with various bacterial and fungal groups. In each case, the factor could be plausibly explained as directly affecting common scab symptoms. For instance, lower scab severity in the conventionally managed fields may reflect chemical control measures, although the dominant practices in the state, fumigation with metam sodium and seed treatment with fungicides, generally do not provide strong control of this bacterial pathogen.

These associations could all represent direct causal effects that independently influence common scab infection and severity, but these factors could also act on other variables that, in turn, have a direct effect on disease occurrence and severity. Therefore, we developed a path analysis model structure that incorporated these a priori constraints but otherwise, allowed the data to determine the strength of the other direct and indirect relationships. The strongest model indicated that potato market class membership and the composition of the soil bacterial community had the strongest direct effects on common scab severity, with a more minor direct contribution of soil chemical variables. Farm management and soil chemistry acted indirectly on common scab severity. Common scab severity tended to be higher on organically managed fields, but this could be primarily explained by the strong correlation between management practice and soil type. Similarly, soil chemistry primarily affected common scab severity indirectly through its effects on bacterial community composition. Soils with less OM and more acidic $\mathrm{pH}$ contained bacterial communities that had relatively low diversity at the phyla level and a greater relative abundance of Actinobacteria, the one bacterial phylum displaying a significant negative correlation with common scab severity in

TABLE 1. Permutation multivariate analysis of variance results

\begin{tabular}{|c|c|c|c|c|c|c|}
\hline \multirow[b]{2}{*}{ Taxonomic resolution } & \multirow[b]{2}{*}{ Microbial group } & \multirow[b]{2}{*}{$\begin{array}{l}\text { Pseudo- } \\
\quad F\end{array}$} & \multirow[b]{2}{*}{$R^{2}$} & \multicolumn{3}{|c|}{ Permutation $^{\mathrm{a}}$} \\
\hline & & & & $\begin{array}{c}\text { Unconstrained } \\
P \text { value }\end{array}$ & $\begin{array}{c}\text { Stratified within } \\
\text { market class } P \text { value }\end{array}$ & $\begin{array}{c}\text { Stratified within management } \\
\text { practice } P \text { value }\end{array}$ \\
\hline $\mathbf{A S V} \mathbf{V}^{b}$ & Bacteria & 2.099 & 0.070 & 0.0001 & 0.0002 & 0.0006 \\
\hline ASV & Fungi & 2.662 & 0.087 & 0.0005 & 0.0004 & 0.0097 \\
\hline Genus & Bacteria & 4.159 & 0.129 & 0.0001 & 0.0003 & 0.0001 \\
\hline Genus & Fungi & 3.067 & 0.099 & 0.0014 & 0.0022 & 0.0176 \\
\hline Phyla & Bacteria & 6.400 & 0.186 & 0.0002 & 0.0001 & 0.0001 \\
\hline Phyla & Fungi & 2.774 & 0.090 & 0.0757 & 0.1081 & 0.2580 \\
\hline
\end{tabular}

a Analysis was based on Bray-Curtis dissimilarities calculated at three levels of taxonomic resolution. Permutation refers to three strategies for constraining permutations for calculating effect $P$ values. Unconstrained allowed complete permutation among all samples. Stratified within market class allowed permutations only within a given potato market class (russet or white/yellow). Stratified within management practice allow permutations only within management categories (conventional versus organic).

b Bold text indicates effects with $P<0.05$. ASV, amplicon sequence variant. 
isolation. Fungal communities did not have a notable direct relationship with common scab severity; it is likely that the correlation observed in isolation was accounted for by the shared responses of bacterial and fungal communities to management and soil chemistry.

Given that soil bacterial community composition was the strongest direct predictor of common scab symptoms, we explored the particular compositional differences associated with high or low scab. Bacterial community composition primarily aligned with a gradient that reflected soil texture and management practice from sandier, lower-OM soils with primarily conventional management to loamier, richer soils with more organically managed fields. Compositional variation along this gradient was apparent at very coarse taxonomic levels, including shifts in the diversity and relative abundance of whole bacterial phyla, particularly a shift from codominance by Actinobacteria and Proteobacteria on the sandy, conventional end of the spectrum to codominance by Acidobacteria and Proteobacteria along with a number of more minor phyla on the rich, organic end. Common scab severity was lower in soils with high abundance of Actinobacteria, in particular with two genera in the Actinomycetales, in line with substantial research on the inhibitory properties of nonpathogenic members of this order (Hiltunen et al. 2009; Liu et al. 1995; Schottel et al. 2001; Wanner et al. 2014). The Janthinobacterium and Bacillus genera were also negatively associated with common scab severity. Although we cannot determine from correlations alone whether these genera had direct negative interactions with the $S$. scabies pathogen, other studies have documented antibiotic properties of some members of these genera (Baricz et al. 2018; Becker et al. 2009; Beneduzi et al. 2012; Choudhary and Johri 2009; Cui et al. 2019).

This observational study has several constraints that limit the strength of our conclusions. The spatial correlation in distribution of organically and conventionally managed farms across soil types limits our ability to distinguish the role of management practices from inherent soil properties. However, this observation reflects the real decisions being made by growers in the state of Wisconsin and may reflect underlying forces that influence production success in these soil types. In a similar vein, soil microbial communities vary in numerous aspects among fields, and therefore, we cannot

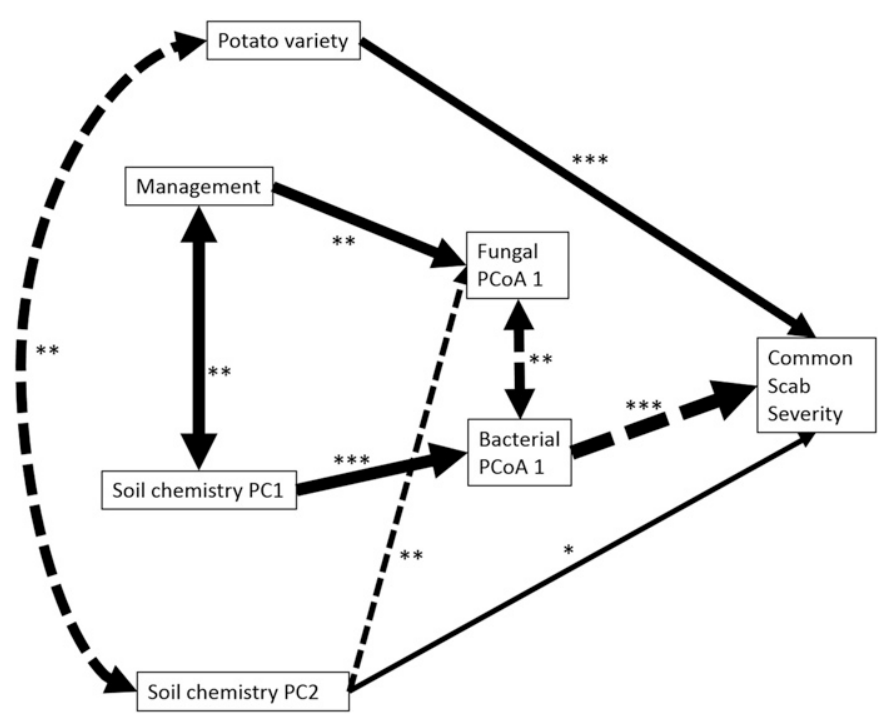

Fig. 4. Path diagram relating field attributes to common scab symptoms. Only statistically significant $(P<0.05)$ regression coefficients from the optimal model are shown. Arrow width reflects effect sizes. Double-headed arrows represent correlations (no causal relationship posited). Unidirectional arrows indicate posited causal directions. Solid lines represent positive relationships, whereas dashed lines represent negative relationships. PC, principal component; PCoA, principal coordinates analysis. $* P<0.05$; $* * P<0.01$; $* * * P<$ 0.001 . conclusively attribute disease levels to any particular microbial taxa without further controlled experimentation. Finally, to search for general patterns, we summarized variables in broad categories, although there could be substantial variation within these groups. For instance, although potato market classes do represent genetically distinct clades (Hirsch et al. 2013), phenotypic traits, including resistance to common scab, vary among cultivars within classes (Braun et al. 2017). Additionally, organic versus conventional management practices vary in many respects in Wisconsin, and practices also vary substantially within these categories in a number of ways (Colquhoun et al. 2017). Thus, it is not possible in this study to pinpoint the precise factors driving differences in common scab severity between categories.

We did not quantify the size of the $S$. scabies populations in field soils, and therefore, it is unclear if the lower scab severity found in some fields reflected low inoculum of the pathogen in soil or other processes that inhibit disease development on tubers. Moreover, $S$. scabies populations in soil are not the only potential source of inoculum because $S$. scabies can be present on the seed potato pieces (Webster et al. 2018). Seed potatoes are specifically grown with the purpose of generating seed, and there is a standardized process of certification of seed potatoes to ensure varietal purity and reduction in disease spread. However, seed potatoes are not free of all potato-pathogenic microbes and can be a source of inoculum introduction of some diseases, such as common scab, in the production field. Common scab is not a regulated disease, but high disease severity observed as high tuber blemish on seed potato tubers could be a reason for a seed lot to lose its classification and/or certification as seed. It is critical that disease management in seed potato crops is optimal to reduce inoculum introduction into production fields, but in practice, it is not possible to eradicate all common pathogens from seed potatoes in field-grown generations of seed potatoes. We did not investigate the source of the $S$. scabies present in the fields in this study, but it is possible that $S$. scabies populations resident in soils may have a stronger or different response to soil microbial communities compared with seedborne inoculum. For instance, soil microbial communities may have a weaker suppressive effect on seedborne inoculum if these pathogens have a "head start" on plant infection. Additionally, little is known about the nonpathogenic microbial communities present on seed potatoes and what role these communities may play in disease development or crop health in general.

Maintaining soil conditions that are inhospitable to pathogens is an important component of any integrated pest management strategy for control of soilborne diseases, but the effects of management actions on soil suppression of pathogens are still poorly understood. In this study, we found that variation in common scab severity across Wisconsin potato fields correlated with all measured aspects of the farming system. However, by considering intercorrelations between these variables, we show that disease symptoms were most directly responsive to potato cultivars and soil bacterial communities. Based on these results, management strategies for controlling common scab need to be evaluated in light of mechanistic understanding-practices that directly or indirectly shape soil microbial communities toward certain states are likely to be the most effective at reducing disease loads.

\section{LITERATURE CITED}

Baricz, A., Teban, A., Chiriac, C. M., Szekeres, E., Farkas, A., Nica, M., Dascalu, A., Oprisan, C., Lavin, P., and Coman, C. 2018. Investigating the potential use of an Antarctic variant of Janthinobacterium lividum for tackling antimicrobial resistance in a One Health approach. Sci. Rep. 8: 15272 .

Becker, M. H., Brucker, R. M., Schwantes, C. R., Harris, R. N., and Minbiole, K. P. C. 2009. The bacterially produced metabolite violacein is associated with survival of amphibians infected with a lethal fungus. Appl. Environ. Microbiol. 75:6635-6638. 
Beneduzi, A., Ambrosini, A., and Passaglia, L. M. P. 2012. Plant growthpromoting rhizobacteria (PGPR): Their potential as antagonists and biocontrol agents. Genet. Mol. Biol. 35:1044-1051.

Benjamini, Y., and Hochberg, Y. 1995. Controlling the false discovery rate-a practical and powerful approach to multiple testing. J. R. Stat. Soc. B 57: 289-300.

Bolyen, E., Rideout, J. R., Dillon, M. R., Bokulich, N. A., Abnet, C., Al-Ghalith, G. A., Alexander, H., Alm, E. J., Arumugam, M., Asnicar, F., Bai, Y., Bisanz, J. E., Bittinger, K., Brejnrod, A., Brislawn, C. J., Brown, C. T., Callahan, B. J., Caraballo-Rodríguez, A. M., Chase, J., Cope, E., Da Silva, R., Dorrestein, P. C., Douglas, G. M., Durall, D. M., Duvallet, C., Edwardson, C. F., Ernst, M., Estaki, M., Fouquier, J., Gauglitz, J. M., Gibson, D. L., Gonzalez, A., Gorlick, K., Guo, J., Hillmann, B., Holmes, S., Holste, H., Huttenhower, C., Huttley, G., Janssen, S., Jarmusch, A. K., Jiang, L., Kaehler, B., Kang, K. B., Keefe, C. R., Keim, P., Kelley, S. T., Knights, D., Koester, I., Kosciolek, T., Kreps, J., Langille, M. G., Lee, J., Ley, R., Liu, Y., Loftfield, E., Lozupone, C., Maher, M., Marotz, C., Martin, B. D., McDonald, D., McIver, L. J., Melnik, A. V., Metcalf, J. L., Morgan, S. C., Morton, J., NaimeyA. T., Navas-Molina, J. A., Nothias, L. F., Orchanian, S. B., Pearson, T., Peoples, S. L., Petras, D., Preuss, M. L., Pruesse, E., Rasmussen, L. B., Rivers, A., Robeson, M. S., II, Rosenthal, P., Segata, N., Shaffer, M., Shiffer, A., Sinha, R., Song, S. J., Spear, J. R., Swafford, A. D., Thompson, L. R., Torres, P. J., Trinh, P., Tripathi, A., Turnbaugh, P. J., Ul-Hasan, S., van der Hooft, J. J., Vargas, F., Vázquez-Baeza, Y., Vogtmann, E., von Hippel, M., Walters, W., Wan, Y., Wang, M., Warren, J., Weber, K. C., Williamson, C. H., Willis, A. D., Xu, Z. Z., Zaneveld, J. R., Zhang, Y., Zhu, Q., Knight, R., and Caporaso, J. G. 2019. Reproducible, interactive, scalable, and extensible microbiome data science using QIIME 2. Nat. Biotech. 37:852-857.

Braun, S., Gevens, A., Charkowski, A., Allen, C., and Jansky, S. 2017. Potato common scab: A review of the causal pathogens, management practices, varietal resistance screening methods, and host resistance. Am. J. Potato Res. 94:283-296.

Callahan, B. J., McMurdie, P. J., Rosen, M. J., Han, A. W., Johnson, A. J., and Holmes, S. P. 2016. DADA2: High-resolution sample inference from Illumina amplicon data. Nat. Methods 13:581-583.

Caporaso, J. G., Lauber, C. L., Walters, W. A., Berg-Lyons, D., Lozupone, C. A., Turnbaugh, P. J., Fierer, N., and Knight, R. 2011. Global patterns of $16 \mathrm{~S}$ rRNA diversity at a depth of millions of sequences per sample. Proc. Natl. Acad. Sci. USA 108(Supplement 1):4516-4522.

Choudhary, D. K., and Johri, B. N. 2009. Interactions of Bacillus spp. and plants: With special reference to induced systemic resistance (ISR). Microbiol. Res. 164:493-513.

Colquhoun, J. B., Gevens, A. J., Groves, R. L., Heider, D. J., Jensen, B. M., Nice, G. R. W., and Ruark, M. D. 2017. Commercial Vegetable Production in Wisconsin. University of Wisconsin Extension, Madison, WI.

Cui, W. Y., He, P. J., Munir, S., He, P. B., Li, X. Y., Li, Y. M., Wu, J. J., Wu, Y. X., Yang, L. J., He, P. F., and He, Y. Q. 2019. Efficacy of plant growth promoting bacteria Bacillus amyloliquefaciens B9601-Y2 for biocontrol of southern corn leaf blight. Biol. Control 139:104080.

FAO. 2014. FAOSTAT Database Collections. Food and Agriculture Organization of the United States, Rome, Italy.

Ge, T. D., Nie, S. A., Wu, J. S., Shen, J. L., Xiao, H. A., Tong, C. L., Huang, D. F., Hong, Y., and Iwasaki, K. 2011. Chemical properties, microbial biomass, and activity differ between soils of organic and conventional horticultural systems under greenhouse and open field management: A case study. J. Soils Sediments 11:25-36.

Glenn, T. C., and Faircloth, B. 2013. Welcome to EHS DNA Laboratory. University of Georgia. baddna.uga.edu

Grace, J. B. 2006. Structural Equation Modelling and Natural Systems. Cambridge University Press, Cambridge, United Kingdom.

Hiltunen, L. H., Ojanpera, T., Kortemaa, H., Richter, E., Lehtonen, M. J., and Valkonen, J. P. T. 2009. Interactions and biocontrol of pathogenic Streptomyces strains co-occurring in potato scab lesions. J. Appl. Microbiol. 106:199-212.

Hirsch, C. N., Hirsch, C. D., Felcher, K., Coombs, J., Zarka, D., Van Deynze, A., De Jong, W., Veilleux, R. E., Jansky, S., Bethke, P., Douches, D. S., and Buell, C. R. 2013. Retrospective view of North American potato (Solanum tuberosum L.) breeding in the 20th and 21st centuries. G3 Genes Genomes Genetics 3:1003-1013.

Lankau, R. A., and Keymer, D. P. 2016. Ectomycorrhizal fungal richness declines towards the host species' range edge. Mol. Ecol. 25:3224-2341.

Liu, D. Q., Anderson, N. A., and Kinkel, L. L. 1995. Biological-control of potato scab in the field with antagonistic Streptomyces scabies. Phytopathology 85:827-831.
Lorang, J. M., Liu, D., Anderson, N. A., and Schottel, J. L. 1995. Identification of potato scab inducing and suppressive species of Streptomyces. Phytopathology 85:261-268.

Loria, R., Kers, J., and Joshi, M. 2006. Evolution of plant pathogenicity in Streptomyces. Annu. Rev. Phytopathol. 44:469-487.

Meng, Q. X., Yin, J. F., Rosenzweig, N., Douches, D., and Hao, J. J. J. 2012. Culture-based assessment of microbial communities in soil suppressive to potato common scab. Plant Dis. 96:712-717.

Mizuno, N., Yoshida, H., Nanzyo, M., and Tadano, T. 1998. Chemical characterization of conducive and suppressive soils for potato scab in Hokkaido, Japan. Soil Sci. Plant Nutr. 44:289-295.

Neeno-Eckwall, E. C., Kinkel, L. L., and Schottel, J. L. 2001. Competition and antibiosis in the biological control of potato scab. Can. J. Microbiol. 47:332-340.

Nilsson, R. H., Larsson, K.-H., Taylor, A. F. S., Bengtsson-Palme, J., Jeppesen, T. S., Schigel, D., Kennedy, P., Picard, K., Glöckner, F. O., Tedersoo, L., Saar, I., Kõljalg, U., and Abarenkov, K. 2019. The UNITE database for molecular identification of fungi: Handling dark taxa and parallel taxonomic classifications. Nucleic Acids Res. 47:D259-D264.

Norris, C. E., and Congreves, K. A. 2018. Alternative management practices improve soil health indices in intensive vegetable cropping systems: A review. Front. Environ. Sci. 6:50.

Oksanen, J., Blanchet, F. G., Kindt, R., Legendre, P., Minchin, P. R., O-Hara, R. B., Simpson, G. L., Solymos, P., Stevens, M. H. M., and Wagner, H. 2015. vegan: Community Ecology Package. R package version 2.3-1. http:// CRAN.R-project.org/package=vegan

Parada, A. E., Needham, D. M., and Fuhrman, J. A. 2016. Every base matters: Assessing small subunit rRNA primers for marine microbiomes with mock communities, time series and global field samples. Environ. Microbiol. 18: 1403-1414.

Powelson, M., and Rowe, R. 2008. Managing diseases caused by seedborne and soilborne fungi and fungus-like pathogens. Pages 183-195 in: Potato Health Management. D. Johnson, ed. American Phytopathological Society, St. Paul, MN.

Rosenzweig, N., Tiedje, J. M., Quensen, J. F., Meng, Q. X., and Hao, J. J. J. 2012. Microbial communities associated with potato common scabsuppressive soil determined by pyrosequencing analyses. Plant Dis. 96: 718-725.

Ryan, A. D., Kinkel, L. L., and Schottel, J. L. 2004. Effect of pathogen isolate, potato cultivar, and antagonist strain on potato scab severity and biological control. Biocontrol Sci. Technol. 14:301-311.

Sagova-Mareckova, M., Daniel, O., Omelka, M., Kristufek, V., Divis, J., and Kopecky, J. 2015. Determination of factors associated with natural soil suppressivity to potato common scab. PLoS One 10:e0116291.

Schottel, J. L., Shimizu, K., and Kinkel, L. L. 2001. Relationships of in vitro pathogen inhibition and soil colonization to potato scab biocontrol by antagonistic Streptomyces spp. Biol. Control 20:102-112.

Sun, P. P., Otto-Hanson, L. K., Arenz, B. E., Ma, Q., and Kinkel, L. L. 2015. Molecular and functional characteristics of streptomycete communities in relation to soil factors and potato common scab. Eur. J. Soil Biol. 70:58-66.

Toju, H., Tanabe, A. S., Yamamoto, S., and Sato, H. 2012. High-coverage ITS primers for the DNA-based identification of ascomycetes and basidiomycetes in environmental samples. PLoS One 7:e40863.

Wang, Q., Garrity, G. M., Tiedje, J. M., and Cole, J. R. 2007. Naive Bayesian classifier for rapid assignment of rRNA sequences into the new bacterial taxonomy. Appl. Environ. Microbiol. 73:5261-5267.

Wanner, L. A. 2009. A patchwork of Streptomyces species isolated from potato common scab lesions in North America. Am. J. Potato Res. 86:247-264.

Wanner, L. A., Kirk, W. W., and Qu, X. S. 2014. Field efficacy of nonpathogenic Streptomyces species against potato common scab. J. Appl. Microbiol. 116:123-133.

Webster, B. J., Chen, Y., and Gevens, A. J. 2018. Impact of seed cutting and seed-borne inoculum on daughter tuber common scab and plant growth. Am. J. Potato Res. 95:191-198.

White, T. J., Bruns, T., Lee, S., and Taylor, J. W. 1990. Amplification and direct sequencing of fungal ribosomal RNA genes for phylogenetics. Pages 315-325 in: PCR Protocols: A Guide to Methods and Applications. M. A. Innis, D. H. Gelfand, J. J. Snisky, and T. J. White, eds. Academic Press, Inc., New York, NY.

Xue, D., Christenson, R., Genger, R., Gevens, A., and Lankau, R. A. 2018. Soil microbial communities reflect both inherent soil properties and management practices in Wisconsin potato fields. Am. J. Potato Res. 95: 696-708.

Yves, R. 2012. lavann: An R package for structural equation modeling. J. Stat. Softw. 48:1-36. 